\title{
Countervailing effects of atrazine on water recreation: How do recreators evaluate them?
}

\author{
Dietrich Earnhart \\ Department of Economics, University of Kansas, Lawrence, Kansas, USA
}

Val Smith

Department of Ecology and Evolutionary Biology, University of Kansas, Lawrence, Kansas, USA

Received 22 July 2002; revised 19 November 2002; accepted 19 November 2002; published 2 April 2003.

[1] This paper examines the countervailing effects of atrazine on water recreational choices. The presence of atrazine in waterbodies potentially reduces the symptoms of eutrophication, which is a condition of low water quality due to nutrient enrichment. Eutrophication frequently undermines recreational enjoyment and diminishes recreational use of affected waterbodies. Thus increased atrazine concentrations could induce greater recreation. However, atrazine also potentially decreases the mass and size of fish populations; this loss potentially reduces recreational use. To examine empirically these countervailing effects on recreational use, this study gathers and generates data on actual recreation under initial water quality conditions and stated recreation under hypothetical quality conditions, which vary eutrophication-related and fish-related quality independently and jointly. This economic study uses a travel cost framework and the associated contingent behavior framework to analyze these data. INDEX TERMS: 1803 Hydrology: Anthropogenic effects; 1845 Hydrology: Limnology; 1871 Hydrology: Surface water quality; 6314 Policy Sciences: Demand estimation; 6344 Policy Sciences: System operation and management; KEYWORDS: atrazine, water recreation demand, eutrophication, fish

Citation: Earnhart, D., and V. Smith, Countervailing effects of atrazine on water recreation: How do recreators evaluate them?, Water Resour. Res., 39(4), 1081, doi:10.1029/2002WR001598, 2003.

\section{Introduction}

[2] In the United States, the impoundments created by approximately 65,000 public and private dams are used extensively for recreation, flood control, irrigation, and drinking water [U.S. Army Corps of Engineers, 1998]. Water quality in these reservoirs can vary widely, however, due to pollutant inputs [Canfield and Bachmann, 1981; Straskraba et al., 1993; Kennedy and Thornton, 2001]. Our study focuses on one class of pollutants, herbicides, and their effects on water quality, including their effects on the symptoms of eutrophication, which results from excess inputs of another class of pollutants, nutrients. To explore these effects, we examine Clinton Lake, a $31 \mathrm{~km}^{2}$ reservoir that is located near Lawrence, Kansas.

[3] Human activities cause significant transport of nitrogen and phosphorus from agricultural watersheds [Carpenter et al., 1998]. The subsequent enrichment of surface waters by these nutrients results in eutrophication-related problems that include nuisance algal growth [Smith et al., 1998]. Eutrophication seriously degrades aquatic ecosystems and impairs their use for boating, swimming, fishing, and other human uses [Carpenter et al., 1998]. However, eutrophic lakes and reservoirs often generate higher total sportfish yields than less productive waterbodies [Jones and Hoyer, 1982]. Thus a moderate degree of cultural eutrophi-

Copyright 2003 by the American Geophysical Union. 0043-1397/03/2002WR001598 cation could generate greater benefits for persons who care about fish populations, especially anglers or environmentally-conscious recreators who perceive fish health as an overall indicator of health for aquatic life in general. Consequently, nutrient controls designed to reduce nuisance algal growth, while improving water transparency and smell (i.e., reducing odor), may potentially reduce the average body size and total abundance of fish populations [Ney, 1996; Maceina, 2001]. Therefore restriction of nutrient inputs can increase one key dimension of overall water quality, algae-related quality (water transparency and smell), while simultaneously decreasing another important dimension, fish-related quality (average body size and total abundance). Thus recreational users of the water resource must consider a potentially very important trade-off prompted by nutrient loading reductions.

[4] In addition to nutrients, the agricultural application of pesticides can result in the delivery of potentially harmful toxicants from croplands into local streams and river channels. Our study focuses on one type of pesticide: atrazine, one of the most heavily used pesticides in the US [Delvo and Hanthorn, 1983]. As a preemergent herbicide, atrazine is heavily used for weed control in corn and sorghum fields [Solomon et al., 1996]. Once applied, atrazine can be transported from the land to receiving waters. Jayachandran et al. [1994] report that $40 \%$ of the samples collected from agricultural tile drains contained atrazine at concentrations greater than the U.S. Environmental Protection Agency's maximum concentration level (MCL) of $3 \mathrm{ug} / \mathrm{L}$. Atrazine 
has been frequently detected in rivers, streams, lakes, and reservoirs throughout the US and Canada at concentrations ranging from $<1 \mathrm{ug} / \mathrm{L}$ to $>70 \mathrm{ug} / \mathrm{L}$ [Solomon et al., 1996].

[5] By their very nature, herbicides such as atrazine can reduce the symptoms of eutrophication by directly inhibiting the nuisance growth of aquatic plants. Atrazine has been shown to inhibit the growth of phytoplankton algae and rooted aquatic plants at parts per billion concentrations [deNoyelles et al., 1982; Nelson et al., 1999]. However, these direct controls on plant growth unfortunately can translate into indirect negative effects on sport fish populations that feed on plant-associated aquatic insects [Randtke and deNoyelles, 1985; deNoyelles et al., 1989]. These indirect effects of atrazine on fishes reinforce the potential trade-off faced by recreational users: the presence of high atrazine concentrations could improve water transparency and smell, yet diminish the average body size and total abundance of sportfish populations in eutrophic reservoirs [Ney, 1996; Maceina, 2001]. Thus agricultural inputs of atrazine to Midwestern reservoirs potentially can have countervailing effects on water quality. Such trade-offs could influence reservoir use by recreators.

[6] Our study examines the effects of these specific countervailing water quality changes upon recreational choices. In particular, we study residents of Lawrence, Kansas, and their visitation of nearby Clinton Lake. Using these data, we consider three research issues related to the countervailing effects of atrazine on water quality and the subsequent effects on recreational choices. First, we briefly assess recreators' abilities to evaluate a trade-off between quality dimensions. In particular, we explore recreators' abilities to assess orthogonal changes in two water quality dimensions (i.e., one dimension changes, while the other remains unchanged) and countervailing changes in two water quality dimensions (i.e., one dimension increases, while the other decreases). Second, we examine the net effect of atrazine on recreational use: positive, negative, or neutral. Third, we calculate and compare the effects of the individual water quality dimensions on recreational choices. In particular, we identify the implicit rate of exchange between the two dimensions.

[7] By examining recreators' responses to these potential trade-offs involving water quality, our analysis sheds new light on the societal valuation of water resources. This improved understanding facilitates well-informed ecological and political debates regarding water quality management.

\section{Economic Analysis of Water Quality Effects}

[8] Hundreds of economic studies examine the effect of water quality on various types of economic behavior [e.g., Smith and Desvousges, 1986]. In particular, numerous economic studies examine the effect of water quality on recreational choices [e.g., Huang et al., 1997]. However, only one previously published study considers the effects of multidimensional water quality on recreational choices [Ribaudo and Epp, 1984]. This dearth of consideration most likely stems from three potential challenges to economic analysis posed by multidimensional quality.

[9] In the first potential analytical challenge, multiple water quality dimensions are highly positively correlated, i.e., water quality generally degrades or improves in all relevant dimensions simultaneously. In this case, analysis assesses the individual effects of quality dimensions on recreational choices with great difficulty. In particular, this multicollinearity across factors undermines accurate estimation of individual coefficients in multivariate analysis including the generation of coefficients with wrong signs and/or implausible magnitudes [Greene, 1997]. Fortunately, any strong positive correlation among individual quality dimensions would permit the use of a single index to capture the overall effect of water quality on recreational choices [Mitchell and Carson, 1993]. If proportionality applies across all the relevant individual dimensions, then the use of a single index works perfectly.

[10] In the second potential analytical challenge, different water quality dimensions are not correlated. In particular, changes in individual water quality dimensions may be roughly orthogonal to each other. In other words, water quality may improve in one dimension but not improve in other dimensions. In this case, consumers of water quality (e.g., recreators) may evaluate quality improvement in only one dimension at a time. While this case greatly improves the ability of the economic analysis to discern the individual effect of each dimension, this possibility forces consumers to consider unidimensional aspects of water quality, which may be difficult to discern and evaluate, especially their effects on recreational choices.

[11] In the third analytical challenge, different water quality dimensions are negatively correlated, i.e., changes in water quality are countervailing. In this case, consumers of water quality must consider trade-offs between two (or more) dimensions, i.e., evaluate improvement in one dimension, while evaluating degradation in another dimension. This condition potentially undermines consumers' abilities to evaluate the effects of countervailing water quality changes on recreational choices because consumers may or may not be able to assess adequately the associated trade-offs. Our paper briefly explores how well consumers consider, evaluate, and act upon such trade-offs. More important, our paper calculates the rate of exchange that consumers accept between one water quality dimension and another.

[12] Similar to consumers' difficulties, countervailing quality changes also undermine the ability of economic analysis to assess the effects of individual water quality dimensions, as well as the overall effect of water quality, on recreational choices. Strong correlation, whether positive or negative, undermines a model's ability to discern individual effects. Negative correlation in this context eliminates use of a single index for capturing overall quality effects on recreational choices. This paper confronts this challenge and successfully discerns both individual and overall effects of water quality by incorporating complemental information into the statistical analysis.

[13] Economic studies predominantly use travel cost analysis to examine recreational choices by establishing a relationship between individuals' chosen visitation frequency to a recreational site and the implicit "price" of enjoying the site: travel costs (e.g., automobile depreciation). This paper explicitly addresses the trade-off between quality dimensions by combining the travel cost analysis with contingent behavior analysis. The travel cost method analyzes actual behavior. Contingent behavior analysis 
builds upon the travel cost structure by asking recreators about their intended visitation frequency under hypothetical circumstances, in particular, simultaneous changes in the two water quality dimensions of interest. More specifically, our study first records the actual visitation frequency to a certain recreational site. Then it records hypothetical changes in visitation frequency caused by three hypothetical changes in water quality: (1) reduction only in one dimension, (2) improvement only in the other dimension, and (3) countervailing changes in the two dimensions. The first two changes represent orthogonal changes in water quality. Their hypothetical construction is necessary because such completely independent changes do not likely exist in nature. While countervailing changes do occur naturally, their hypothetical construction permits joint estimation of the responses to all three changes. Moreover, responses to the third change identify the overall effect of atrazine on recreation. To link properly water quality to the recorded actual and hypothetical choices, our study controls for variation in travel costs and demographic factors, which also affect recreational use.

[14] As a platform for examining these issues, this paper considers the countervailing effects of atrazine on water quality. As noted above, while increased atrazine potentially decreases plant growth, including nuisance plant growth associated with eutrophication, increased atrazine also potentially decreases the average body size and total abundance of fish populations.

\section{Data Collection and Site Description}

[15] To address the research issues listed above, our paper empirically examines recreational choices made by residents of Lawrence, KS. In particular, we surveyed their actual and hypothetical recreation at Clinton Lake, a reservoir located near Lawrence, KS. Recreators use this reservoir extensively for boating, fishing, camping, and swimming. Clinton Lake is highly eutrophic due to nutrient inputs from agricultural runoff. Consequently, it frequently exhibits intense summer algal blooms [Wang et al., 1999]. Agricultural runoff also transports numerous pesticides to the lake. Observable concentrations of the herbicide atrazine in the lake water range from $<1$ to $14 \mathrm{ug} / \mathrm{L}$ [deNoyelles, 2000]. These atrazine inputs can potentially cause the countervailing effects on water quality that we propose and analyze.

[16] The survey instrument was developed according to the responses of one focus group and a pretest of 20 respondents. To acquire the proper information, we hired the Survey Center of the Policy Research Institute at the University of Kansas to phone randomly residents of Lawrence, KS, during the latter two weeks of September 2000, and first week of October 2000. To ensure useful responses, the survey interviewed only adults. Of the 378 people contacted, 254 completed the survey, for a $67 \%$ response rate. (The sample results would match results of a survey of the full population of Lawrence residents within \pm 4.6 percentage points with $95 \%$ confidence.)

[17] The economic section of the survey instrument first elicited information on the respondents' use of Clinton Lake: ex post visitation (previous 12 months) and specific locations on the lake generally visited (i.e., entry point). Ex post visitation represents actual behavior. Next the survey instrument described the current water quality conditions related to algae levels and fish populations: "Currently, algae reduces the water clarity of Clinton Lake. Starting in late spring, visibility drops from 5 feet to 3 feet in the main body of the lake and visibility drops to 6 inches in the outlying regions of the lake. The algae generate a noticeably earthy smell, which is subtle in the main body and heavily apparent in the outlying regions. Clinton Lake also has fish. On average, anglers catch fish at a rate of 2.25 fish per hour weighing 0.5 pounds." After describing the current conditions, the economic section elicited information on respondents' future or ex ante behavior under these initial conditions: (1) Knowing these conditions, do you plan to visit Clinton Lake in the next 12 months? (2) If so, approximately how many times would you say you plan to visit Clinton Lake? Future or ex ante behavior represents contingent behavior since it is contingent upon current conditions being maintained over the forthcoming 12 months.

[18] Then the survey elicited information on respondents' contingent behavior under two separate sets of hypothetical circumstances: (1) reduction in algae growth that improves visibility by $\mathrm{z} \%$ and makes the associated earthy smell $\mathrm{z} \%$ less noticeable (i.e., the smell is barely noticeable in the main body and only apparent in the outlying regions); and (2) $10 \%$ reduction in the fish catch rate and fish average weight. The degree of algae-related improvement, $z \%$, was randomly and evenly varied across the sample of respondents: $\mathrm{z} \in\{10 \%, 20 \%, 50 \%, 80 \%\}$. Based on a focus group and a priori expectations, the value of $10 \%$ reduction in fish-related quality and noted values of algae-related improvement seemed plausible. Moreover, the 10\% fishrelated quality reduction seemed sufficient to affect visitation yet not strong enough to dominate recreational choices at all levels of algae-related quality improvement. While the survey could have also varied the degree of fish-related quality reduction, this additional variation is unnecessary to explore the trade-off between the two quality dimensions in various combinations. In addition, greater reductions in fish-related quality would not have affected nonvisitors (44.9\% of the sample).

[19] After the description of each hypothetical circumstance, the survey instrument elicited respondents' reactions: (1) Under these new conditions, would you change your planned visitation? (2) If yes, in which direction and by how many visits approximately? Finally, the survey connected an increase in atrazine concentration with the same two sets of hypothetical circumstances described above. In this case, the two circumstances apply jointly, creating a context of countervailing quality changes. Again, the survey elicited responses: (1) Under these new conditions, would you change your planned visitation? (2) If yes, in which direction and by how many visits approximately? Collectively, the respondents' choices under the current water quality conditions and the hypothetical conditions represent contingent behavior.

[20] The latter set of questions force the respondent to reexamine its intended visitation rather than reconsider in hindsight its previously chosen visitation. Consequently, the responses are linked to the reported ex ante visitation. This approach seems more appropriate for a contingent frame- 
Table 1a. Statistical Summary of Variables: Discrete Variables ${ }^{\mathrm{a}}$

\begin{tabular}{llrr}
\hline \multicolumn{1}{c}{ Variable } & \multicolumn{1}{c}{ Value } & Number & Percent \\
\hline Age & $18-19$ & 12 & 5.6 \\
Age & $20 \mathrm{~s}$ & 77 & 35.7 \\
Age & $30 \mathrm{~s}$ & 44 & 20.4 \\
Age & $40 \mathrm{~s}$ & 29 & 13.4 \\
Age & $50 \mathrm{~s}$ & 21 & 9.7 \\
Age & $60 \mathrm{~s}$ & 13 & 6.0 \\
Age & $70 \mathrm{~s}$ & 16 & 7.4 \\
Age & $80 \mathrm{~s}$ & 4 & 1.9 \\
Living arrangement & single & 89 & 41.2 \\
Living arrangement & married/partnered & 127 & 58.8 \\
Children in household & yes & 76 & 35.2 \\
Children in household & no & 140 & 64.8 \\
Student & yes & 70 & 32.4 \\
Student & no & 146 & 67.6 \\
\hline
\end{tabular}

${ }^{\mathrm{a}}$ Number of observations is 216 .

work since respondents, especially nonvisitors, may not be fully aware of current water quality conditions. (As in the present study, Huang et al. [1997] use contingent behavior questions that force the respondent to reexamine its intended visitation under a hypothetical increase in water quality.) The demographic section of the survey instrument gathered information on the following components: age, living arrangement (including marital status), presence of children in household, location by zip code, student status, employment status including the distinction between hourly and salaried workers, hourly wage or annual salary, and average weekly hours worked if paid by hour.

[21] From these reported data, we generate two additional variables. First, we calculate respondents' travel costs associated with recreating at Clinton Lake. Travel costs represent the sum of transport costs, time costs, and access fees. Round-trip transport costs equal the product of twoway travel distance and 31.5 cents per mile, the IRS official rate of auto travel reimbursement for 2000. Travel distance is measured by the road distance between the centroid of each respondent's reported zip code and each respondent's reported entry point for accessing Clinton Lake.

[22] For those reporting multiple entry points, we use the furthest entry point when calculating travel distances. For those reporting no entry points, including those respondents who did not visit Clinton Lake in the preceding 12 months and do not intend to visit in the forthcoming 12 months, we use the average entry point when calculating travel distances. This analysis assumes that all entry points provide a uniform level of water quality for recreational purposes. Therefore the analysis implicitly assumes that some respondents travel greater distances in order to enjoy the same recreational site, as measured by water quality, regardless of their starting point.

[23] Time costs equal the product of two-way travel time and each respondent's implicit value of time per hour. We calculate travel time by assuming a travel speed of $25 \mathrm{MPH}$ within the city limits. Outside of the city limits, travel time to each entry point is based on values provided by officials at Clinton State Park, which is located on the shores of Clinton Lake. (To confirm the validity of these reported travel times, we also calculated the travel times to each entry point by applying the relevant speed limits for paved and gravel road segments to the appropriate travel distances.) To measure the value of time for each respondent, we
Table 1b. Statistical Summary of Variables: Continuous Variables $^{\mathrm{a}}$

\begin{tabular}{|c|c|c|}
\hline Variable & Mean & $\begin{array}{l}\text { Standard } \\
\text { Deviation }\end{array}$ \\
\hline Income $(\$)$ & 16,446 & 21,553 \\
\hline Travel costs $(\$)$ & 22.43 & 12.99 \\
\hline Ex post visits & 3.23 & 7.80 \\
\hline Ex ante visits without quality change & 3.65 & 8.39 \\
\hline Change in visit level: fish only quality change & -0.461 & 3.111 \\
\hline Change in visit level: algae only quality change & 2.741 & 6.259 \\
\hline Change in visit level: combined quality change & -0.579 & 3.317 \\
\hline Ex ante visit level with fish only quality change & 3.19 & 7.11 \\
\hline Ex ante visit level with algae only quality change & 5.84 & 11.41 \\
\hline Ex ante visit level with combined quality change & 3.17 & 7.08 \\
\hline
\end{tabular}

${ }^{\mathrm{a}}$ Number of observations is 216 .

use the midpoint of each respondent's identified wage bracket or salary bracket (except the bottom bracket, where the top point is used, and the top bracket, where the bottom point is used) after dividing salary by 2,000 hours per year; i.e., 50 work weeks $\times 40$ hours per week. Access fees equal $\$ 1$ per person.

[24] In addition, we calculate annual income for each respondent. For salaried workers, annual income equals their annual salary. For hourly workers, income is the product of hourly wage and average weekly hours.

[25] The data collection process provides complete information on the needed variables for 216 of the 254 respondents who completed the survey. (Full documentation on the database is available upon request from the contact author.) Tables 1a, $1 \mathrm{~b}$, and $1 \mathrm{c}$ describe the gathered information for those 216 respondents. As shown, the modal respondent is between 20 and 29 years old, married or living with a partner, barren (i.e., without children), and not a student. The average respondent earns approximately $\$ 16,500$ per year, faces travel costs of $\$ 22$, visited Clinton Lake about 3 times in the preceding year, and intends to visit about 4 times in the forthcoming year given current water quality conditions. The change in algae-related water quality induces an average increase of 2.7 visits. The change in fishrelated quality induces an average decrease of 0.5 visits. The combination of quality changes induces an average decrease of 0.6 visits.

[26] Table 1c displays the mean magnitude of visitation changes for each type of quality change. Regardless of the algae-related quality improvement level, the mean is significantly positive; the overall mean is also significantly pos-

Table 1c. Statistical Summary of Variables: Significance of Mean Responses to Quality Changes Relative to Zero

\begin{tabular}{clrrc}
\hline Algae Level & Quality Type & Mean & T Statistic & Probability \\
\hline All & fish & -0.461 & -2.17 & 0.031 \\
All & algae & 2.741 & 4.36 & 0.001 \\
10 & algae & 3.333 & 2.49 & 0.016 \\
20 & algae & 1.349 & 4.64 & 0.001 \\
50 & algae & 2.358 & 2.37 & 0.021 \\
80 & algae & 1.872 & 2.72 & 0.009 \\
All & combined & -0.579 & -2.46 & 0.015 \\
10 & combined & -1.255 & -2.03 & 0.048 \\
20 & combined & -0.095 & -0.41 & 0.682 \\
50 & combined & -0.151 & -0.94 & 0.351 \\
80 & combined & -0.532 & -1.18 & 0.243 \\
\hline
\end{tabular}


itive. The mean response to fish-related quality reduction is significantly negative. The mean response to combined quality changes is negative regardless of the algae-related improvement level. This prompted reduction is significantly less than zero only when algae-related quality improves the least amount of $10 \%$. Therefore the reduction of fish-related quality dominates at this lowest level of algae-related improvement. The insignificant results for the remaining levels of algae-related improvement indicate a degree of indifference between the initial and new set of quality conditions prompted by the countervailing quality changes. This indifference is logically found at the higher levels of algae-related improvement.

[27] The overall mean response to combined quality changes is significantly negative, as shown in Table 1c. The strong response to the combination of $10 \%$ algaerelated improvement and fish-related reduction must be sufficient to generate an significant reduction in visitation in general. Based on a focus group and a priori expectations, a $10 \%$ reduction in fish-related quality seemed small enough to generate positive changes in visitation levels when combined with the higher levels of algae-related quality improvements, namely $50 \%$ and $80 \%$. Surprisingly, even this seemingly small decline dominates choices in the context of countervailing quality changes.

\section{Analysis of Rationality and Consistency of Visitation Responses}

[28] This section briefly scrutinizes the recreational responses to water quality changes. In particular, it examines the logic or rationality of each individual choice and explores the consistency across choices for a single respondent. This examination must analyze respondents who intend to visit Clinton Lake under the initial conditions as well as those who do not intend to visit since an improvement in algae-related quality, in isolation or in combination with the fish-related quality reduction, may induce initial nonvisitors to visit under the new and improved quality conditions.

[29] To assess the rationality and consistency of individual responses, we first consider respondents' indicated desire to modify planned visitation and the direction of this modification in response to new water quality conditions. The lack of desire to change visitation levels represents a zero directional change. Rationally, a decrease in fishrelated quality should prompt a nonpositive change in visitation. However, eight respondents increase visitation in response to this quality reduction. Of course, these eight respondents may not like fish; the presence of fish may undermine their recreational enjoyment. The magnitude of these positive responses is less than or equal to five for all but one respondent. The remaining respondent increases visitation by 24 visits in response to the fish-related quality reduction. This extreme response undermines much of the statistical analysis; therefore we exclude it when necessary.

[30] Conversely, an increase in algae-related quality should prompt a nonnegative change in visitation. Only one respondent decreases visitation in response to this quality increase; moreover, the reduction is only one visit and is induced by the smallest increase in algae-related quality. At the other extreme, in response to a $10 \%$ improvement in algae-related quality, one respondent doubles his/ her visitation level from 100 to 200. This extreme response undermines the statistical analysis; therefore we exclude it when necessary.

[31] Next, we assess the consistency across all three responses for each respondent. In particular, we examine the two responses associated with orthogonal changes in water quality (i.e., only fish-related and only algae-related) to form expectations about the one response to the countervailing quality change. If neither orthogonal change induces a nonzero directional change, one would expect no change in response to the combined quality change. However, six of the possible 125 respondents fail to meet this expectation. Similarly, a positive response to improved algae-related quality, yet a zero response to reduced fish-related quality, would seem to predict a positive response to the combined quality change. Only nine of the 62 relevant respondents meet this expectation. Oddly, 13 of the 62 respondents reduce their visitation in response to the combined quality change. Certainly, this set of responses indicates an inconsistency. Conversely, when lower fish-related quality induces lower visitation yet higher algae-related quality induces no change, one would expect a lower visitation level in response to combined quality changes. Three of the six relevant respondents meet this expectation.

[32] We also assess consistency across all three responses for each respondent by examining the magnitudes of responses to new water quality conditions. To be consistent, respondents should respond more strongly (in a positive sense) to the combined quality change than to the fishrelated quality reduction and more strongly to algae-related improvements than to the combined quality change. Twenty-two of the 216 respondents fail to meet the first expectation. Three respondents fail to meet the second expectation.

[33] In sum, these noted results question respondents' abilities to assess, evaluate, and respond to single and multiple changes in water quality, especially countervailing changes. These irrationalities and inconsistencies notwithstanding (except the two noted exceptions), multivariate analysis is still able to identify the individual effects of fishand algae-related quality on recreational choices and calculate a rate of trade-off between the two types of quality.

\section{Multivariate Analysis of Visitation Responses}

\subsection{Model of Visitation Demand}

[34] To guide the multivariate analysis of visitation responses, we construct a basic model of recreation demand. This model assumes that individual $i$ allocates his/her income $\mathrm{y}_{\mathrm{i}}$ between a composite commodity $\mathrm{c}_{\mathrm{i}}$ and a recreation good $\mathrm{q}_{\mathrm{i}}$. This allocation depends on the price of the recreation good, denoted $\mathrm{p}_{\mathrm{i}}$ and titled "travel costs", demographic factors, denoted $x_{i}$, and the water quality level. Given the focus on multidimensional water quality, we specify two water quality variables: $f_{i}$ and $a_{i}$, which respectively denote the fish-related water quality level and the algae-related water quality level. The ordinary Marshallian demand function associated with the recreation good is the following:

$$
\mathrm{q}_{\mathrm{i}}=\mathrm{h}\left(\mathrm{p}_{\mathrm{i}}, \mathrm{y}_{\mathrm{i}}, \mathrm{x}_{\mathrm{i}}, \mathrm{f}_{\mathrm{i}}, \mathrm{a}_{\mathrm{i}} ; \beta\right)+\varepsilon_{\mathrm{i}},
$$

where $\beta$ is the vector of unknown parameters and $\varepsilon_{\mathrm{i}}$ is the additive stochastic term. 
[35] For generality and testing purposes, we construct each visitation response under particular water quality conditions, including initial conditions, as stemming from a separate demand equation; i.e., preferences are allowed to vary across the respondents' consideration of various water quality levels. The demand equations associated with initial water quality conditions, reduced fish-related quality, increased algae-related quality, and reduced fish-related quality in combination with increased algae-related quality are shown below:

Initial quality conditions

$$
\mathrm{q}_{\mathrm{i}}^{\mathrm{o}}=\mathrm{h}^{\mathrm{o}}\left(\mathrm{p}_{\mathrm{i}}, \mathrm{y}_{\mathrm{i}}, \mathrm{x}_{\mathrm{i}}, \mathrm{f}_{\mathrm{i}}, \mathrm{a}_{\mathrm{i}} ; \beta\right)+\varepsilon_{\mathrm{i}}^{\mathrm{o}},
$$

Decreased fish-related quality

$$
\mathrm{q}_{\mathrm{i}}^{\mathrm{f}}=\mathrm{h}^{\mathrm{f}}\left(\mathrm{p}_{\mathrm{i}}, \mathrm{y}_{\mathrm{i}}, \mathrm{x}_{\mathrm{i}}, \mathrm{f}_{\mathrm{i}}, \mathrm{a}_{\mathrm{i}} ; \beta\right)+\varepsilon_{\mathrm{i}}^{\mathrm{f}},
$$

Increased algae-related quality

$$
\mathrm{q}_{\mathrm{i}}^{\mathrm{a}}=\mathrm{h}^{\mathrm{a}}\left(\mathrm{p}_{\mathrm{i}}, \mathrm{y}_{\mathrm{i}}, \mathrm{x}_{\mathrm{i}}, \mathrm{f}_{\mathrm{i}}, \mathrm{a}_{\mathrm{i}} ; \beta\right)+\varepsilon_{\mathrm{i}}^{\mathrm{a}},
$$

Combination of quality changes

$$
\mathrm{q}_{\mathrm{i}}^{\mathrm{c}}=\mathrm{h}^{\mathrm{c}}\left(\mathrm{p}_{\mathrm{i}}, \mathrm{y}_{\mathrm{i}}, \mathrm{x}_{\mathrm{i}}, \mathrm{f}_{\mathrm{i}}, \mathrm{a}_{\mathrm{i}} ; \beta\right)+\varepsilon_{\mathrm{i}}^{\mathrm{c}} .
$$

Note that construction of four equations permits the coefficients and the variance associated with the error terms to vary across the four equations.

[36] Intended demand under initial conditions represents levels of demand. Analysis of these data cannot identify the effects of water quality on recreation since quality does not vary. Instead, the analysis must focus on data for changes in demand.

[37] Responses to the three contingent behavior questions regarding new water quality conditions represent changes in demand. Appropriately, the empirical analysis estimates these changes: $\Delta q_{i}^{f}, \Delta q_{i}^{\mathrm{a}}$, and $\Delta q_{i}^{\mathrm{c}}$, where $\Delta$ denotes a change in demand. The chosen question format purposively focuses on the link between changes in quality and changes in demand; the chosen analytical approach is completely consistent with this question format.

[38] For the empirical analysis, we specify the functional form of demand in linear form:

$$
\begin{aligned}
\mathrm{q}_{\mathrm{i}}^{\mathrm{k}}= & \alpha^{\mathrm{k}}+\beta_{\mathrm{p}}^{\mathrm{k}} \mathrm{p}_{\mathrm{i}}^{\mathrm{k}}+\beta_{\mathrm{y}}^{\mathrm{k}} \mathrm{y}_{\mathrm{i}}^{\mathrm{k}}+\beta_{\mathrm{x}}^{\mathrm{k}} \mathrm{x}_{\mathrm{i}}^{\mathrm{k}}+\beta_{\mathrm{f}}^{\mathrm{k}} \mathrm{f}_{\mathrm{i}}^{\mathrm{k}}+\beta_{\mathrm{a}}^{\mathrm{k}} \mathrm{a}_{\mathrm{i}}^{\mathrm{k}}+\beta_{\mathrm{fy}}^{\mathrm{k}}\left(\mathrm{f}_{\mathrm{i}} \mathrm{y}_{\mathrm{i}}\right)^{\mathrm{k}} \\
& +\beta_{\mathrm{ay}}^{\mathrm{k}}\left(\mathrm{a}_{\mathrm{i}} \mathrm{y}_{\mathrm{i}}\right)^{\mathrm{k}}+\beta_{\mathrm{fx}}^{\mathrm{k}}\left(\mathrm{f}_{\mathrm{i}} \mathrm{x}_{\mathrm{i}}\right)^{\mathrm{k}}+\beta_{\mathrm{ax}}^{\mathrm{k}}\left(\mathrm{a}_{\mathrm{i}} \mathrm{x}_{\mathrm{i}}\right)^{\mathrm{k}}+\varepsilon_{\mathrm{i}}^{\mathrm{k}},
\end{aligned}
$$

where $k \in\{0, f, a, c\}$. In this linear specification, water quality levels and demographic factors, as well as the interactions between these two sets of regressors, enter as explanatory variables. Without the interactive terms, the magnitude of changes in visitation would not depend on demographic factors.

[39] Given this construction, absolute changes in stated demand, $\Delta \mathrm{q}_{\mathrm{i}}^{\mathrm{k}}$, relate to absolute changes in one or two of the quality components, $\Delta \mathrm{f}_{\mathrm{i}}^{\mathrm{k}}$ and $\Delta \mathrm{a}_{\mathrm{i}}^{\mathrm{k}}$, and any associated demographic factors in the following way:

$$
\begin{aligned}
\Delta \mathrm{q}_{\mathrm{i}}^{\mathrm{k}}= & \beta_{\mathrm{f}}^{\mathrm{k}} \Delta \mathrm{f}_{\mathrm{i}}^{\mathrm{k}}+\beta_{\mathrm{a}}^{\mathrm{k}} \Delta \mathrm{a}_{\mathrm{i}}^{\mathrm{k}}+\beta_{\mathrm{fy}}^{\mathrm{k}}\left(\Delta \mathrm{f}_{\mathrm{i}}^{\mathrm{k}} \mathrm{y}_{\mathrm{i}}\right)+\beta_{\mathrm{ay}}^{\mathrm{k}}\left(\Delta \mathrm{a}_{\mathrm{i}}^{\mathrm{k}} \mathrm{y}_{\mathrm{i}}\right)+\beta_{\mathrm{fx}}^{\mathrm{k}}\left(\Delta \mathrm{f}_{\mathrm{i}}^{\mathrm{k}} \mathrm{x}_{\mathrm{i}}\right) \\
& +\beta_{\mathrm{ax}}^{\mathrm{k}}\left(\Delta \mathrm{a}_{\mathrm{i}}^{\mathrm{k}} \mathrm{x}_{\mathrm{i}}\right)+\mu_{\mathrm{i}}^{\mathrm{k}},
\end{aligned}
$$

where $\mathrm{k} \in\{0, \mathrm{f}, \mathrm{a}, \mathrm{c}\}$. Multivariate analysis estimates the four equations on demand change separately:

$$
\begin{aligned}
\Delta \mathrm{q}_{\mathrm{i}}^{0}= & \beta_{\mathrm{f}}^{0} \Delta \mathrm{f}_{\mathrm{i}}^{0}+\beta_{\mathrm{a}}^{0} \Delta \mathrm{a}_{\mathrm{i}}^{0}+\beta_{\mathrm{fx}}^{0}\left(\Delta \mathrm{f}_{\mathrm{i}}^{0} \mathrm{x}_{\mathrm{i}}\right)+\beta_{\mathrm{ax}}^{0}\left(\Delta \mathrm{a}_{\mathrm{i}}^{0} \mathrm{x}_{\mathrm{i}}\right)+\beta_{\mathrm{fy}}^{0}\left(\Delta \mathrm{f}_{\mathrm{i}}^{0} \mathrm{y}_{\mathrm{i}}\right) \\
& +\beta_{\mathrm{ay}}^{0}\left(\Delta \mathrm{a}_{\mathrm{i}}^{0} \mathrm{y}_{\mathrm{i}}\right)+\mu_{\mathrm{i}}^{0}, \\
\Delta \mathrm{q}_{\mathrm{i}}^{\mathrm{f}}= & \beta_{\mathrm{f}}^{\mathrm{f}} \Delta \mathrm{f}_{\mathrm{i}}^{\mathrm{f}}+\beta_{\mathrm{a}}^{\mathrm{f}} \Delta \mathrm{a}_{\mathrm{i}}^{\mathrm{f}}+\beta_{\mathrm{fx}}^{\mathrm{f}}\left(\Delta \mathrm{f}_{\mathrm{i}}^{\mathrm{f}} \mathrm{x}_{\mathrm{i}}\right)+\beta_{\mathrm{ax}}^{\mathrm{f}}\left(\Delta \mathrm{a}_{\mathrm{i}}^{\mathrm{f}} \mathrm{x}_{\mathrm{i}}\right)+\beta_{\mathrm{fy}}^{\mathrm{f}}\left(\Delta \mathrm{f}_{\mathrm{i}}^{\mathrm{f}} \mathrm{y}_{\mathrm{i}}\right) \\
& +\beta_{\mathrm{ay}}^{\mathrm{f}}\left(\Delta \mathrm{a}_{\mathrm{i}}^{\mathrm{f}} \mathrm{y}_{\mathrm{i}}\right)+\mu_{\mathrm{i}}^{\mathrm{f}},
\end{aligned}
$$

$$
\begin{aligned}
\Delta \mathrm{q}_{\mathrm{i}}^{\mathrm{a}}= & \beta_{\mathrm{f}}^{\mathrm{a}} \Delta \mathrm{f}_{\mathrm{i}}^{\mathrm{a}}+\beta_{\mathrm{a}}^{\mathrm{a}} \Delta \mathrm{a}_{\mathrm{i}}^{\mathrm{a}}+\beta_{\mathrm{fx}}^{\mathrm{a}}\left(\Delta \mathrm{f}_{\mathrm{i}}^{\mathrm{a}} \mathrm{x}_{\mathrm{i}}\right)+\beta_{\mathrm{ax}}^{\mathrm{a}}\left(\Delta \mathrm{a}_{\mathrm{i}}^{\mathrm{a}} \mathrm{x}_{\mathrm{i}}\right)+\beta_{\mathrm{fy}}^{\mathrm{a}}\left(\Delta \mathrm{f}_{\mathrm{i}}^{\mathrm{a}} \mathrm{y}_{\mathrm{i}}\right) \\
& +\beta_{\mathrm{ay}}^{\mathrm{a}}\left(\Delta \mathrm{a}_{\mathrm{i}}^{\mathrm{a}} \mathrm{y}_{\mathrm{i}}\right)+\mu_{\mathrm{i}}^{\mathrm{a}},
\end{aligned}
$$

$$
\begin{aligned}
\Delta \mathrm{q}_{\mathrm{i}}^{\mathrm{c}}= & \beta_{\mathrm{f}}^{\mathrm{c}} \Delta \mathrm{f}_{\mathrm{i}}^{\mathrm{c}}+\beta_{\mathrm{a}}^{\mathrm{c}} \Delta \mathrm{a}_{\mathrm{i}}^{\mathrm{c}}+\beta_{\mathrm{fx}}^{\mathrm{c}}\left(\Delta \mathrm{f}_{\mathrm{i}}^{\mathrm{c}} \mathrm{x}_{\mathrm{i}}\right)+\beta_{\mathrm{ax}}^{\mathrm{c}}\left(\Delta \mathrm{a}_{\mathrm{i}}^{\mathrm{c}} \mathrm{x}_{\mathrm{i}}\right)+\beta_{\mathrm{fy}}^{\mathrm{c}}\left(\Delta \mathrm{f}_{\mathrm{i}}^{\mathrm{c}} \mathrm{y}_{\mathrm{i}}\right) \\
& +\beta_{\mathrm{ay}}^{\mathrm{c}}\left(\Delta \mathrm{a}_{\mathrm{i}}^{\mathrm{c}} \mathrm{y}_{\mathrm{i}}\right)+\mu_{\mathrm{i}}^{\mathrm{c}},
\end{aligned}
$$

where $\mu_{\mathrm{i}}^{0}, \mu_{\mathrm{i}}^{\mathrm{f}}, \mu_{\mathrm{i}}^{\mathrm{a}}$, and $\mu_{\mathrm{i}}^{\mathrm{c}}$, are the additive stochastic terms for the equations on demand changes. Note that $\Delta \mathrm{a}_{\mathrm{i}}=0$ in equation (4c), $\Delta \mathrm{fi}=0$ in equation (4d), and both equal 0 in equation (4b). Therefore we cannot estimate equation (4b).

[40] After estimating each plausible equation separately, the multivariate analysis pools equations (4c), (4d), and (4e) into one single equation (where " $p$ " denotes pooled):

$$
\begin{aligned}
\Delta \mathrm{q}_{\mathrm{i}}^{\mathrm{p}}= & \beta_{\mathrm{f}}^{\mathrm{p}} \Delta \mathrm{f}_{\mathrm{i}}^{\mathrm{p}}+\beta_{\mathrm{a}}^{\mathrm{p}} \Delta \mathrm{a}_{\mathrm{i}}^{\mathrm{p}}+\beta_{\mathrm{fx}}^{\mathrm{p}}\left(\Delta \mathrm{f}_{\mathrm{i}}^{\mathrm{p}} \mathrm{x}_{\mathrm{i}}\right)+\beta_{\mathrm{ax}}^{\mathrm{p}}\left(\Delta \mathrm{a}_{\mathrm{i}}^{\mathrm{p}} \mathrm{x}_{\mathrm{i}}\right)+\beta_{\mathrm{fy}}^{\mathrm{p}}\left(\Delta \mathrm{f}_{\mathrm{i}}^{\mathrm{p}} \mathrm{y}_{\mathrm{i}}\right) \\
& +\beta_{\mathrm{ay}}^{\mathrm{p}}\left(\Delta \mathrm{a}_{\mathrm{i}}^{\mathrm{p}} \mathrm{y}_{\mathrm{i}}\right)+\mu_{\mathrm{i}}^{\mathrm{p}} .
\end{aligned}
$$

To estimate this equation, we employ a random effects model [Hsiao, 1986], which takes into account the panel structure of the data: three observations for each recreator. This model captures differences across the various recreators by incorporating an individual term, $\nu_{\mathrm{i}}$, for each respondent $i$. In the random effects model, this individual term is uncorrelated with the other regressors in equation (5a). Consequently, $\nu_{i}$ represents a random disturbance term that remains constant across the multiple responses for a given recreator and captures the effects of excluded factors specific to each respondent. A reformulation of equation (5a) generates the random effects model:

$$
\begin{aligned}
\Delta \mathrm{q}_{\mathrm{i}}^{\mathrm{p}}= & \beta_{\mathrm{f}}^{\mathrm{p}} \Delta \mathrm{f}_{\mathrm{i}}^{\mathrm{p}}+\beta_{\mathrm{a}}^{\mathrm{p}} \Delta \mathrm{a}_{\mathrm{i}}^{\mathrm{p}}+\beta_{\mathrm{fx}}^{\mathrm{p}}\left(\Delta \mathrm{f}_{\mathrm{i}}^{\mathrm{p}} \mathrm{x}_{\mathrm{i}}\right)+\beta_{\mathrm{ax}}^{\mathrm{p}}\left(\Delta \mathrm{a}_{\mathrm{i}}^{\mathrm{p}} \mathrm{x}_{\mathrm{i}}\right)+\beta_{\mathrm{fy}}^{\mathrm{p}}\left(\Delta \mathrm{f}_{\mathrm{i}}^{\mathrm{p}} \mathrm{y}_{\mathrm{i}}\right) \\
& +\beta_{\mathrm{ay}}^{\mathrm{p}}\left(\Delta \mathrm{a}_{\mathrm{i}}^{\mathrm{p}} \mathrm{y}_{\mathrm{i}}\right)+\nu_{\mathrm{i}}+\mu_{\mathrm{i}}^{\mathrm{p}} .
\end{aligned}
$$

(In essence, the random effects model uses $\nu_{\mathrm{i}}$ to adjust the error structure as a means for accommodating the correlation across the error terms $\mu_{i}^{\mathrm{f}}, \mu_{i}^{\mathrm{a}}$, and $\mu_{\mathrm{i}}^{\mathrm{c}}$ when they are pooled into $\mu_{\mathrm{i}}^{\mathrm{p}}$.)

[41] The data on absolute changes in stated demand include many zeros and consist entirely of integer values. This data structure suggests the use of Poisson regression techniques [Englin and Cameron, 1996], which have been developed to address these nonnormal attributes. The Poisson regression model specifies that each value of the dependent variable is drawn from a Poisson distribution with parameter $\lambda_{i}$, which is a function of the relevant 
Table 2. Poisson Regression Analysis of Absolute Changes in Visitation ${ }^{\mathrm{a}}$

\begin{tabular}{|c|c|c|c|c|}
\hline Variable & Fish & Algae & Combined & Pooled $^{b}$ \\
\hline Fish Quality & $0.038^{\mathrm{c}}(0.019)$ & & $0.020(0.029)$ & $0.052^{\mathrm{d}}(0.013)$ \\
\hline Fish Quality $\times$ Income $(000 s)$ & $-0.0001(0.0002)$ & & $-0.0007^{\mathrm{c}}(0.0004)$ & $0.0002(0.0002)$ \\
\hline Fish Quality $\times$ Age & $0.006^{\mathrm{e}}(0.003)$ & & $-0.007(0.006)$ & $-0.004^{\mathrm{e}}(0.003)$ \\
\hline Fish Quality $\times$ Single & $0.009(0.011)$ & & $-0.027(0.020)$ & $-0.019^{\mathrm{d}}(0.007)$ \\
\hline Fish Quality $\times$ Children & $0.010(0.010)$ & & $0.001(0.018)$ & $0.014^{\mathrm{c}}(0.007)$ \\
\hline Fish Quality $\times$ Student & $0.026^{\mathrm{c}}(0.012)$ & & $0.043^{\mathrm{e}}(0.023)$ & $0.029^{\mathrm{d}}(0.010)$ \\
\hline Algae Quality & & $0.012^{\mathrm{d}}(0.025)$ & $-0.010^{\mathrm{e}}(0.005)$ & $0.011^{\mathrm{c}}(0.005)$ \\
\hline Algae Quality $\times$ Income $(000 s)$ & & $-0.00002(0.00003)$ & $0.0001^{\mathrm{c}}(0.0001)$ & $-0.00001(0.0001)$ \\
\hline Algae Quality $\times$ Age & & $-0.002^{\mathrm{d}}(0.001)$ & $0.002(0.001)$ & $-0.002^{\mathrm{e}}(0.001)$ \\
\hline Algae Quality $\times$ Single & & $-0.007^{\mathrm{d}}(0.002)$ & $0.006(0.005)$ & $-0.006(0.004)$ \\
\hline Algae Quality $\times$ Children & & $-0.003^{\mathrm{c}}(0.002)$ & $0.005(0.004)$ & $-0.002(0.003)$ \\
\hline Algae Quality $\times$ Student & & $0.001(0.002)$ & $-0.002(0.005)$ & $-0.002(0.004)$ \\
\hline Number of Observations & 214 & 214 & 214 & 642 \\
\hline Log likelihood & -284.231 & -765.273 & -313.874 & $-3,375.69$ \\
\hline$\chi^{2}$ Statistic (significance) & $1,450.2(0.000)$ & $1,396.9(0.000)$ & $1,373.7(0.000)$ & $6,751.4(0.000)$ \\
\hline
\end{tabular}

"Standard errors are shown in parentheses. Omitted category for single is "Married/Partnered", for children is "No", and for student is "No". To generate a dependent variable with only nonnegative values, the estimation adds each respondent's intended demand level under initial conditions to its absolute change in visitation. To adjust for this addition, the estimation includes the initially intended demand level as a regressor. This regressor is transformed to conform with the log linear specification of the Poisson model. An additional regressor is included to indicate when this log-transformed regressor is undefined. The table does not report the coefficient estimates for these two regressors.

${ }^{\mathrm{b}}$ Estimation of the pooled data uses a random effects model.

${ }^{\mathrm{c}}$ Statistical significance at the $5 \%$ level.

${ }^{\mathrm{d}}$ Statistical significance at the $1 \%$ level.

${ }^{\text {e }}$ Statistical significance at the $10 \%$ level.

regressors [Greene, 1997]. We define the function for $\lambda_{\mathrm{i}}$ using the most common formulation [Greene, 1997]:

$$
\lambda_{\mathrm{i}}^{\mathrm{k}}=\exp \left\{\mathrm{m}\left(\mathrm{y}_{\mathrm{i}}, \mathrm{x}_{\mathrm{i}}, \Delta \mathrm{f}_{\mathrm{i}}^{\mathrm{k}}, \Delta \mathrm{a}_{\mathrm{i}}^{\mathrm{k}} ; \beta^{\mathrm{k}}\right)\right\}, \text { where } \mathrm{k} \in\{\mathrm{f}, \mathrm{a}, \mathrm{c}, \mathrm{p}\} .
$$

To calibrate the model, we employ maximum likelihood estimation. This procedure identifies the parameters for the constructed function $\mathrm{m}(\bullet)$ that maximize the following likelihood function:

$$
\log \mathrm{L}^{\mathrm{k}}=\Sigma_{\mathrm{i}}-\lambda_{\mathrm{i}}^{\mathrm{k}}+\Delta \mathrm{q}_{\mathrm{i}}^{\mathrm{k}} \mathrm{m}\left(\mathrm{y}_{\mathrm{i}}, \mathrm{x}_{\mathrm{i}}, \Delta \mathrm{f}_{\mathrm{i}}^{\mathrm{k}}, \Delta \mathrm{a}_{\mathrm{i}}^{\mathrm{k}} ; \beta^{\mathrm{k}}\right)-\log \left(\Delta \mathrm{q}_{\mathrm{i}}^{\mathrm{k} !}\right)
$$

where ! denotes use of the factorial [Englin and Cameron, 1996].

[42] The Poisson model implicitly assumes that the variance of the dependent variable, conditional on the regressors, equals the mean of the dependent variable, conditional on the regressors. We test this assumption using a regression-based test for overdispersion devised by Cameron and Trivedi [1990]. The test statistic of 0.266 indicates that we cannot reject the null hypothesis of equality at levels less than $35 \%$. Details on this test are available upon request.

[43] The Poisson regression model requires nonnegative integers for the dependent variable. The data on absolute changes in stated demand includes some negative integer values. Thus we must adjust these data so that each value is nonnegative. To assure that each individual response is nonnegative, we simply add each recreator's intended demand level under initial conditions, $\mathrm{q}_{\mathrm{i}}^{\mathrm{o}}$, to the same recreator's absolute change in stated demand, $\Delta q_{i}^{k}$. By construction, this sum is nonnegative for each respondent. To adjust for the addition of $\mathrm{q}_{\mathrm{i}}^{\mathrm{o}}$, we simply include $\mathrm{q}_{\mathrm{i}}^{\mathrm{o}}$ as a regressor when estimating the Poisson regression model. This technique of adding a variable to the dependent variable, while including this variable as a regressor, is identical to the approach used to estimate a censored model with a variable nonzero limit [Maddala, 1983, p. 159].

[44] We employ these techniques to estimate the constructed equations.

\subsection{Estimation of Each Response Separately}

[45] First, we separately estimate the functional relationship between each visitation response (change in demand) and the noted explanatory variables. The first three columns of Table 2 report the regression results. As expected, an orthogonal decrease in fish-related quality reduces visitation. (In addition, fish-related quality interactions with age and student status are significant: older people and students are both more responsive to fish-related quality changes.) Again, as expected, greater orthogonal improvements in algae-related quality prompts greater increases in visitation. (In addition, algae-related quality interactions with age, living arrangement, and children are significant: older people, single people, and people with children are all less responsive to algae-related quality changes.) As feared, estimation of responses to countervailing quality changes is not able to identify significantly the positive effect of fish-related quality and not able to sign correctly the expected positive effect of algae-related quality on visitation responses. These results are consistent with the effect of multicollinearity on individual coefficient estimates [Greene, 1997]. Similarly, only three of the ten quality-demographic interactions are significant: richer people are less responsive to fish-related quality changes but more responsive to algae-related quality changes; students are more responsive to fish-related quality changes.

\subsection{Panel Estimation of Pooled Visitation Responses}

[46] Estimation of each response separately confirms the expectation that multicollinearity associated with counter- 
vailing quality changes substantially undermines estimation of individual coefficients for the effects of fish-related and algae-related quality. Fortunately, estimation of responses to fish- or algae-related quality changes in isolation generates correct and highly significant coefficient estimates for both quality dimensions and several (six of the ten) quality-demographic interactions. Therefore multivariate analysis can utilize the effective estimation of qualityrelated coefficients from the isolated quality change models to control estimation of the same parameters in the combined quality change model. We control the estimation by pooling the visitation responses into a single response variable and estimating the model parameters (i.e., functional relationship) jointly using a random effects model. This joint model constrains the effect of fish-related quality to be equal between responses to only fish-related quality reductions and responses to combined quality changes: $\beta_{\mathrm{f}}^{\mathrm{f}}=\beta_{\mathrm{f}}^{\mathrm{c}}$. Similarly, the joint model constrains the effect of algae-related quality to be equal between responses to only algae-related quality improvements and responses to combined quality changes: $\beta_{\mathrm{a}}^{\mathrm{a}}=$ $\beta_{\mathrm{a}}^{\mathrm{c}}$. Similar constraints apply to the associated qualitydemographic interactions. These two sets of constraints permit significant estimation and proper identification of quality-related effects on visitation responses. Fortunately, results from a log likelihood ratio test confirm that these constraints are proper; i.e., quality-related effects are not significantly different for responses to combined quality changes. (The log likelihood ratio test statistic of 18.5 , with 12 degrees of freedom, is significant at levels greater than $10 \%$.)

[47] The fourth column of Table 2 reports the estimation results. As hoped, the effects of water quality are highly significant and positive for both dimensions: fish- and algae-related. Moreover, five of the ten quality-demographic interactions are significant. Older people and single people respond less strongly to fish-related quality changes, while people with children and students respond more strongly to fish related quality changes. And older people respond less strongly to algae-related quality changes.

[48] Given the estimation of significantly positive coefficients for both dimensions of water quality in the presence of countervailing quality changes, we can now properly calculate the implied trade-off between fishrelated and algae-related quality. Since both quality dimensions are measured as percent changes from initial levels, the ratio of the two associated coefficients, $\beta_{\mathrm{f}} / \beta_{\mathrm{a}}$, captures the implicit trade-off between quality dimensions: $\beta_{\mathrm{f}} / \beta_{\mathrm{a}}=0.052 / 0.011=4.73$. For each $1 \%$ reduction in fish-related quality, respondents require a $4.7 \%$ increase in algae-related quality in order to maintain their same level of visitation, i.e., same level of recreational enjoyment. This rather large ratio indicates that fishrelated quality dominates algae-related quality in the minds of respondents.

\section{Summary}

[49] Balancing user demands and conflicts for multipleuse public waters such as Clinton Lake is a major challenge for water quality managers [Jones, 1996]. Like many other U.S. reservoirs, Clinton Lake sustains signifi- cant water-based recreation including fishing, a highly valued activity during the warmer months [Riechers and Fedler, 1996]. Also, due to diffuse agricultural inputs, Clinton Lake is eutrophic and frequently contains detectable concentrations of the herbicide atrazine. The presence of this herbicide can potentially generate countervailing effects on water quality, especially if watershed exports of atrazine to the lake should increase in the future. In this study, we examine recreators' responses to these effects to understand recreators' relative valuation of different dimensions of lake water quality.

[50] In our study, we consider three research issues related to the countervailing effects of atrazine on water quality and their subsequent effects on recreational choices by users of Clinton Reservoir. First, we examine the net effect of atrazine on recreational use: positive, negative, or neutral. Even at high levels of algae-related improvement, the net effect of atrazine is uniformly negative. However, this negative effect is only statistically significant at the lowest level of algae-related improvement. Therefore respondents are effectively indifferent between initial quality conditions and a $10 \%$ reduction in fish-related quality given an algaerelated improvement of $20 \%$ or more.

[51] Second, we briefly assess the recreators' abilities to evaluate a trade-off between two fish- and algae-related water quality. In particular, we explore the recreators' abilities to assess a hypothetical set of orthogonal and countervailing changes in these two water quality dimensions.

[52] Third, despite some irrationalities and inconsistencies in respondents' choices, we effectively calculate the individual effects of fish- and algae-related quality on recreational choices. By comparing the two quality-related effects, we identify the implicit rate of exchange between the two dimensions. For each $1 \%$ reduction in fish-related quality, respondents require a $4.7 \%$ increase in algae-related quality in order to maintain their same level of visitation, i.e., maintain their same level of recreational enjoyment.

[53] As stressed by Postel and Carpenter [1997], the value of freshwater ecosystem services, such as those provided by Clinton Lake to Lawrence residents, can be quite large. Estimates of such values can help to clarify the stakes in environmental debates, including the evaluation of proposed water quality management options, where the net social benefits of different alternatives can be quantitatively compared [Carpenter et al., 1997].

[54] Because of its eutrophic status, Clinton Lake will likely be the focus of future watershed nutrient management efforts designed to reduce nutrient inputs and thereby improve algae-related aspects of its water quality [deNoyelles, 2000]. Water quality modeling is currently underway to estimate the probable effects of reduced $\mathrm{P}$ loadings on algae-related water quality in the lake [Wang et al., 1999]. However, reductions in external nutrient loading also potentially can have negative impacts on reservoir fisheries [Ney, 1996], a contrasting effect that could lead to reduced recreational use of this reservoir. It is expected that agricultural activities in the watershed will continue to contribute to atrazine inputs; if true, atrazine concentrations in the lake water may remain stable or increase, which prompts an interesting question.

[55] What effects might such future changes in nutrient and atrazine loadings have upon the use of Clinton Lake? 
We demonstrate here how quantitative economic methods (travel cost analysis and the associated contingent behavior analysis) can be applied to evaluate the responses of recreational users to the multiple outcomes that could result from changes in nutrient and herbicide loading to this waterbody. For example, our analysis of recreators' responses to changes in fish-related versus algae-related quality provides an estimate of the effective rate of exchange between fish- and algae-related water quality in this multiple-use reservoir. As the watershed is managed to decrease nutrient loading to Clinton Reservoir, existing modeling frameworks such as EUTROMOD [Hession et al., 1996] will allow quantitative estimates of the presumptive increases in algae-related water quality. Similarly, empirical models relating nutrients to sport fish yields [see Maceina, 2001, Figure 1] allow quantitative predictions for presumptive decreases in fish-related water quality. Knowing the effective rate of exchange between fish- and algaerelated water quality in Clinton Reservoir will allow reservoir managers to estimate recreators' responses to future changes in the watershed.

[56] In addition, the estimated rate of exchange between fish- and algae-related water quality can help to guide reservoir management choices made by Clinton Lake managers. If managers wish to decrease nutrient loading, they should consider primarily management options that substantially limit the reduction in sport fish yields and substantially enhance the improvement in algae-related water clarity and odor in line with the estimated exchange rate of 1 to 5. In other words, any management option to limit nutrient loading that causes a $1 \%$ reduction in sport fish yields must also prompt a roughly $5 \%$ improvement in algae-related water clarity and odor in order to maintain recreation levels. While management options to limit nutrient loading must address reductions in fish-related water quality, which is relatively more important to recreators, management options to limit atrazine loading actually increase fish-related water quality. Again, managers should focus on management options that are consistent with the estimated exchange rate of 1 to 5. Any management option that causes a $1 \%$ improvement in sport fish yields must also limit to $5 \%$ any reduction in algae-related water clarity and odor in order to maintain recreation levels.

[57] In general, we suggest that the application of the economic tools used here can profitably be merged with empirical and conceptual frameworks for reservoir management. This merger will help improve water quality managers' abilities to predict the benefits of different management options, especially when water resource users face potential trade-offs.

[58] Acknowledgments. The authors thank V. Kerry Smith and David Popp for their helpful feedback. The authors also thank Marian Martinez for her research assistance. In addition, the authors acknowledge the financial assistance of the Research Development Fund of the University of Kansas.

\section{References}

Cameron, A., and P. Trivedi, Regression based tests for overdispersion in the Poisson model, J. Econometrics, 46, 347-364, 1990.

Canfield, D. E., Jr., and R. W. Bachmann, Prediction of total phosphorus concentrations, chlorophyll $a$, and Secchi depths in natural and artificial lakes, Can. J. Fish. Aquat. Sci., 38, 414-423, 1981
Carpenter, S., D. Bolgrien, R. Lathrop, C. Stow, T. Reed, and M. Wilson, Ecological and economic analysis of lake eutrophication by nonpoint source pollution, Austl. J. Ecol., 23, 68-79, 1997.

Carpenter, S. R., N. F. Caraco, D. L. Correll, R. W. Howarth, A. N. Sharpley, and V. H. Smith, Nonpoint pollution of surface waters with phosphorus and nitrogen, Ecol. Appl., 8, 559-568, 1998.

deNoyelles, F., Assessment of Clinton Lake and its watershed, final report, Kansas Biol. Surv., Lawrence, 2000.

deNoyelles, F., W. D. Kettle, and D. E. Sinn, The responses of plankton communities in experimental ponds to atrazine, the most heavily used pesticide in the United States, Ecology, 63, 1285-1293, 1982.

deNoyelles, F., Jr., W. D. Kettle, C. H. Fromm, M. F. Moffett, and S. L. Dewey, Use of experimental ponds to assess the effects of a pesticide on the aquatic environment, in Using Mesocosms to Assess the Aquatic Ecological Risk of Pesticides, Theory and Practice, Misc. Publ. 75 , edited by J. R. Voshell Jr., pp. 41-56, Entomol. Soc. of Am., Lanham, Md., Dec. 1989.

Delvo, H., and M. Hanthorn, Pesticides: Outlook and situation, IOS-2, 23 pp., Econ. Res. Serv., Washington, D. C., 1983.

Englin, J., and T. A. Cameron, Augmenting travel cost models with contingent behavior data: Poisson regression analyses with individual panel data, Environ. Resour. Econ., 7, 133-147, 1996.

Greene, W., Econometric Analysis, 2nd ed., Prentice-Hall, Old Tappan, N. J., 1997.

Hession, W. C., D. E. Storm, C. T. Haan, K. H. Reckhow, and M. D. Smolen, Risk analysis of total maximum daily loads in an uncertain environment using EUTROMOD, Lake Reservoir Manage., 12, 331 347,1996

Huang, J.-C., T. Haab, and J. Whitehead, Willingness to pay for quality improvements: Should revealed and stated preference data be combined?, J. Environ. Econ. Manage., 34, 240-255, 1997.

Jayachandran, K., T. R. Steinheimer, L. Somasundaram, T. B. Moorman, R. S. Kanwar, and J. R. Coats, Occurrence of atrazine and degradates as contaminants of subsurface drainage and shallow groundwater, J. Environ. Qual., 23, 311-319, 1994.

Jones, J. R., and M. V. Hoyer, Sportfish harvest predicted by summer chlorophyll- $a$ concentrations in Midwestern lakes and reservoirs, Trans. Am. Fish. Soc., 111, 176-179, 1982.

Jones, W. W., Balancing recreational user demands and conflicts on multiple use public waters, in Multidimensional Approaches to Reservoir Fisheries Management, edited by L. E. Miranda and D. R. DeVries, Am. Fish. Soc. Symp., 16, 179-185, 1996.

Kennedy, R. H., and K. W. Thornton, Water quality indicators for reservoirs: A conceptual framework, J. Lake Reservoir Manage., 17, 188196, 2001.

Maceina, M. J., Trophic state and fish in Alabama reservoirs, LakeLine, 21 16-19, 2001.

Maddala, G. S., Limited-Dependent and Qualitative Variables in Econometrics, Cambridge Univ. Press, New York, 1983.

Mitchell, R. C., and R. T. Carson, The value of clean water: The public's willingness to pay for boatable, fishable, and swimmable quality water, Water Resour. Res., 29, 2445-2454, 1993.

Nelson, K. J., K. D. Hoagland, and B. D. Siegfried, Chronic effects of atrazine on tolerance of a benthic diatom, Environ. Toxicol. Chem., 18, $1038-1045,1999$.

Ney, J. J., Oligotrophication and its discontents: Effects of reduced nutrient loading on reservoir fisheries, in Multidimensional Approaches to Reservoir Fisheries Management, edited by L. E. Miranda and D. R. DeVries, Am. Fish. Soc. Symp., 16, 285-295, 1996.

Postel, S. L., and S. R. Carpenter, Freshwater ecosystem services, in Nature's Services, edited by G. C. Daily, pp. 195-214, Island Press, Washington, D. C., 1997.

Randtke, S. J., and F. deNoyelles, A critical assessment of the influence of management practices on water quality, water treatment, and sport fishing in multipurpose reservoirs in Kansas, Contrib. 252, Kansas Water Resour. Res. Inst., Univ. of Kansas, Lawrence, Sept. 1985.

Ribaudo, M., and D. Epp, The importance of sample discrimination in using the travel cost demand method to estimate benefits of improved water quality, Land Econ., 60, 397-403, 1984.

Riechers, R. K., and A. J. Fedler, An overview of economic impact and value of recreational fisheries, in Multidimensional Approaches to Reservoir Fisheries Management, edited by L. E. Miranda and D. R. DeVries, Am. Fish. Soc. Symp., 16, 245-250, 1996.

Smith, V. K., and W. H. Desvousges, Measuring Water Quality Benefits, Kluwer Acad., Norwell, Mass., 1986. 
Smith, V. H., G. D. Tilman, and J. C. Nekola, Eutrophication: Impacts of excess nutrients on freshwater, marine, and terrestrial ecosystems, Environ. Pollut., 100, 179-196, 1998.

Solomon, K., et al., Ecological risk assessment of atrazine in North American surface waters, Environ. Toxicol. Chem, 15, 31-76, 1996.

Straskraba, M., J. Tundisi, and A. Duncan, State-of-the-art of reservoir limnology and water quality management, in Comparative Reservoir Limnology and Water Quality Management, edited by M. Straskraba, J. G. Tundisi, and A. Duncan, pp. 213-288, Kluwer Acad., Norwell, Mass., 1993.

U.S. Army Corps of Engineers, National inventory of dams, Office of the Chief, Washington, D. C., 1998.
Wang, S. H., D. G. Huggins, F. deNoyelles, and W. S. Koln, An analysis of the trophic state of Clinton Lake, J. Lake Reservoir Manage., 15, 239$250,1999$.

D. Earnhart, Department of Economics, University of Kansas, 213 Summerfield Hall, Lawrence, KS 66045, USA. (earnhart@ku.edu)

V. Smith, Department of Ecology and Evolutionary Biology, University of Kansas, 6007 Haworth Hall, Lawrence, KS 66045, USA. (valsmith@ ku.edu) 